\title{
Additional considerations for trace element analysis of environmental matrices using inductively coupled plasma atomic emission spectrometry with ultrasonic nebulization
}

\author{
M. Hoenig ${ }^{1 *}$, H. Dočkalová ${ }^{2}$ and H. Baeten ${ }^{1}$ \\ ${ }^{1}$ CERVA, Leuvensesteenweg 17, 3080-Tervuren, Belgium \\ ${ }^{2}$ Technical University Brno, Faculty of Chemistry, Veslařská 230, 63700-Brno, Czech Republic
}

\begin{abstract}
This work compares efficiencies of pneumatic and ultrasonic nebulizers and discusses drawbacks observed in trace element analyses of environmental matrices using ICP-AES with ultrasonic nebulization. The interference observed is mainly due to variable calcium content in samples; in most cases the excessive plasma loading by $\mathrm{Ca}$ is responsible for signal suppression of analyte elements. Such matrix effect may be managed to a certain extent using a classical internal standardisation that is discussed in details. Under well defined conditions, the ICP-AES-USN analysis of most trace elements leads to accurate results for matrices usually studied. However, due to chemical reactions occurring in the condensation stage of the ultrasonic nebulizer and subsequent analyte losses to the waste, the ICP-AES-USN analysis of copper and particularly of boron has to be avoided because it leads unavoidably to erroneous results. This drawback cannot be resolved by usual means of correction but may be overcome by using conventional pneumatic nebulizers.
\end{abstract}

Keywords. Inductively coupled plasma atomic emission spectrometry - ultrasonic nebulization - trace elements - environmental samples - matrix interference - internal standards.

\section{Introduction}

Since its commercial introduction in the seventies, the utilisation of inductively coupled plasma emission atomic spectrometry (ICP-AES) has grown rapidly and has become an extremely valuable technique for elemental analysis. Due to high sample throughput, wide dynamic range and easiness of use, the ICP-AES applications have extended into many areas of interest, including geological, environmental, agricultural, industrial and biomedical domains. In its initial configuration with pneumatic nebulizers as the mean of sample introduction, a relative freedom from matrix interference was also generally observed. However, comparing ICP-AES performances with more sensitive techniques of atomic spectroscopy (electrothermal atomic absorption spectrometry or inductively coupled plasma-mass spectrometry), it is evident that several analytical situations cannot be afforded because insufficient limits of detection. This limited detection power is essentially due to very low sample transfer to the plasma by the introduction device: a pneumatic nebulizer exhibits a poor efficiency, attaining the percent only. Consequently, more efficient means of sample introduction have been investigated and commercialised: high pressure direct injection nebulizers or more popular ultrasonic nebulizers (USN). In both cases the aerosol formation and transport are more efficient, allowing then a significant improvement of the ICP-AES detection power.

In a previous work also dedicated to trace element analysis of environmental samples [1] we have reported performances and limitations of the routine use of ultrasonic nebulizer as a sample introduction device. As already quoted in the earlier literature concerning USN-ICP-AES [2-5] differences in matrix composition between standards and samples may often lead to changes in efficiency of aerosol formation and transport but they are also responsible for different evolution of phenomena occurring in the plasma itself. These drawbacks are also observed using conventional pneumatic nebulizers but they are less pronounced and may be more easily controlled during the analysis.

Several reported USN problems have been overcome by some improvements in their design, particularly by the recent commercial introduction of autotuned power supply of RF generators, which largely compensates changes in the aerosol formation involved by the variable matrix composition $[1,6-7]$. These works have shown that with autotuned transducers, changes in the acid concentration are well compensated. The influence of main matrix elements is also considerably reduced but not completely eliminated. The only remaining alternative in such conditions is the use of internal standard (IS) correction which compensates for variation

* Correspondence and reprints.

Received February 18, 2000; revised and accepted July 19, 2000. 


\section{Original articles}

in analyte signals intensities affected by phenomena taking place during aerosol formation and transport but also by changes occurring in the plasma. The internal standardisation improves then accuracy but also precision by correcting for various noise sources of the analytical system. Since many of these noise sources affect different analytes similarly, adding an element as an IS permits the emission signal from the analyte to be corrected by monitoring the IS signal. By determination of the ratio of the emission intensities of the analyte and the IS, much of the noise associated with the measurement can be compensated for. Many authors have studied both theoretically and experimentally initial conditions and various parameters associated with selecting acceptable analyte/IS pairs [8-10]. Under well defined analytical conditions (absence of the IS element in samples, high purity of the IS used, precise and repeatable addition of the IS to standard and sample solutions...), the use of many IS elements was tested or recommended: yttrium [11-13], indium [14], lanthanum, lutetium and platinum [1], tungsten [11] and scandium [12,15-17] the latest being nowadays probably the most utilised. Also some works have reported an easier alternative of internal standardisation using argon emission line as internal reference $[18,1]$. In this case of course, only interference effects taking place in the plasma might be corrected because Ar emission intensity is not directly affected by possible phenomena occurring in the sample introduction device.

With objective to replace the time-consuming ETAAS technique by ICP-AES-USN for the routine work (environmental monitoring: plant and fish samples) we have shown in a previous work the relative efficiency of the IS correction using Ar emission line for trace element determinations [1]. It has been concluded that Ar correction may be satisfactory for this type of analysis but that unpredictable errors occur in several cases, especially for samples with very high $\mathrm{Ca}$ content. The aim of present work is to clarify these arguable points and to propose a more universal methodology.

\section{Experimental}

\section{Apparatus}

All measurements were performed using a Liberty 200 ICPAES vacuum spectrometer with a SPS-5 autosampler (Varian, Mulgrave, Australia) fitted with a U-5000AT+ ultrasonic nebulizer (CETAC Technologies, Omaha, NE, USA). V-groove nebulizer with a cyclonic spray chamber (Glass Expansion, Hawthorn, Australia) was used for evaluation and comparison of effects occurring in ultrasonic and pneumatic nebulizers. To avoid clogging of the injection capillary by salts in excess in samples studied, a "high solids" radial torch with a makeup gas (Glass Blowing, Englewood, CO, USA) was used throughout. The main operating conditions are presented in table I. For introduction of internal standard in solution (Sc), the second channel of the Liberty peristaltic pump was used: the sample and the IS flows were
Table I. Instrumental operating conditions for ICP-AES-USN trace element analysis.

\begin{tabular}{|c|c|}
\hline Wavelengths/nm & $\begin{array}{l}\text { analytes: As } 188.9 ; \text { Be } 313.0 ; \\
\text { Cd 228.8; Co 228.6; Cr 267.7; } \\
\text { Cu 324.7; Mo 202.0; Ni 231.6; } \\
\text { Pb 220.4; Sb 206.8; V } 292.4 \\
\text { IS: Ar 425.1; Sc 361.4 }\end{array}$ \\
\hline Background correction & polynomial dynamic mode \\
\hline Torch & radial low flow with gas makeup \\
\hline Observation height $/ \mathrm{mm}$ & 10 above the coil \\
\hline Integration time/s & 5 or 10 \\
\hline Number of replicates & 2 \\
\hline Generator power $/ \mathrm{kW}$ & 1.2 \\
\hline PMT voltage/V & 700 \\
\hline Plasma Ar-flow/l min ${ }^{-1}$ & 16.5 \\
\hline Auxiliary Ar-flow/l min ${ }^{-1}$ & 0.75 \\
\hline Makeup Ar-flow/l min ${ }^{-1}$ & 0.75 \\
\hline Pump speed/rpm & $\begin{array}{l}15 \text { (sample uptake rate } 2 \mathrm{ml} \mathrm{min}^{-1} \text {, } \\
\text { USN and PN) }\end{array}$ \\
\hline Washout time/s & 40 (fast pump on, USN and PN) \\
\hline Nebulizer pressure/kPa & $140(\mathrm{USN}$ and $\mathrm{PN})$ \\
\hline USN heating stage $/{ }^{\circ} \mathrm{C}$ & 140 \\
\hline USN condensation stage $/{ }^{\circ} \mathrm{C}$ & 3 \\
\hline
\end{tabular}

joined just before the entrance capillary of the USN by means of a T-shaped polyethylene piece.

\section{Reagents and materials}

All multielement test solutions were prepared using electronically adjustable micropipets (Rainin, Woburn, MA, USA) from commercially available multielement stock solution (Spectracer, Asnières, France) for trace elements (Be, $\mathrm{Cd}=20 \mu \mathrm{g} / \mathrm{ml}^{-1}$; As, Co, Cr, Cu, Mn, Mo, Ni, Pb, Se, Sb, $\mathrm{Tl}, \mathrm{V}, \mathrm{Zn}=100 \mu \mathrm{g} / \mathrm{ml}^{-1}$ ) or from pure salts (Specpure, Johnson Matthey, London, UK or Merck, Darmstadt, Germany) for main matrix elements $(\mathrm{Ca}, \mathrm{K}, \mathrm{Mg}, \mathrm{P}, \mathrm{Na}$ ). Scandium IS $\left(5 \mu \mathrm{g} / \mathrm{ml}^{-1}\right)$ was prepared from a $1 \mathrm{~g} / \mathrm{l}^{-1}$ stock solution (Chem-Lab, Lichtervelde, Belgium). For all dilutions demineralized redistilled water was used. Final multielement test solutions were acidified to $2 \%$ with nitric acid (Suprapur Merck, Darmstadt, Germany). Real samples utilised for control experiments were various reference samples or samples collected for different monitoring programs of the CERVA (plants and marine organisms) or for the CII [19] (reference plant materials). The mineralization procedure for plant material has been described previously [1] (dry ashing $450{ }^{\circ} \mathrm{C} / 4 \mathrm{~h}$ in platinum crucible, dissolution of ashes with hydrofluoric and nitric acids, evaporation to dryness, final leaching with nitric acid). Fish samples were mineralized similarly but the absence of $\mathrm{Si}$ in their matrix allows skipping the HF-step. 


\section{Results and discussion}

\section{Evaluation of the nebulization efficiency}

The USN is in practice utilised to improve performances of an ICP-AES system. With a such introduction device, an improvement of detection limits by at least one order of magnitude is generally observed in comparison with conventional pneumatic nebulizers $(\mathrm{PN})$.

We have tried to evaluate the actual efficiency of these devices by measuring wasted and really transported solution volumes and by determining the analyte amount losses in the waste (Fig. 1). This scheme indicates that in the case of a PN, a very little part only of the solution introduced is transported to the plasma, showing then a nebulization efficiency of about $3 \%$. The case of the USN is more complicated. First, this nebulization principle allows a better aerosol formation, attaining then a nebulization efficiency of $13 \%$. However, the generated wet aerosol has to be desolvated and supplementary losses occur during the unavoidable condensation stage. As a result of calculations, the actual USN efficiency attains about $9 \%$, a percentage

\section{Pneumatic nebulizer :}

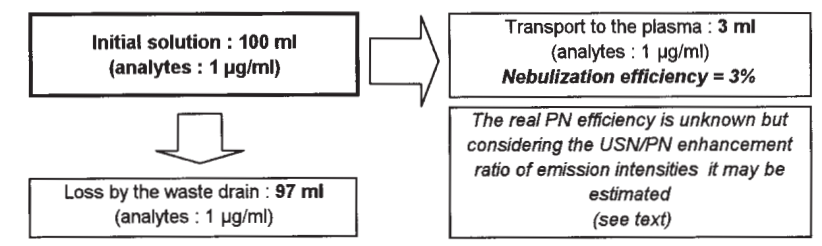

Ultrasonic nebulizer :
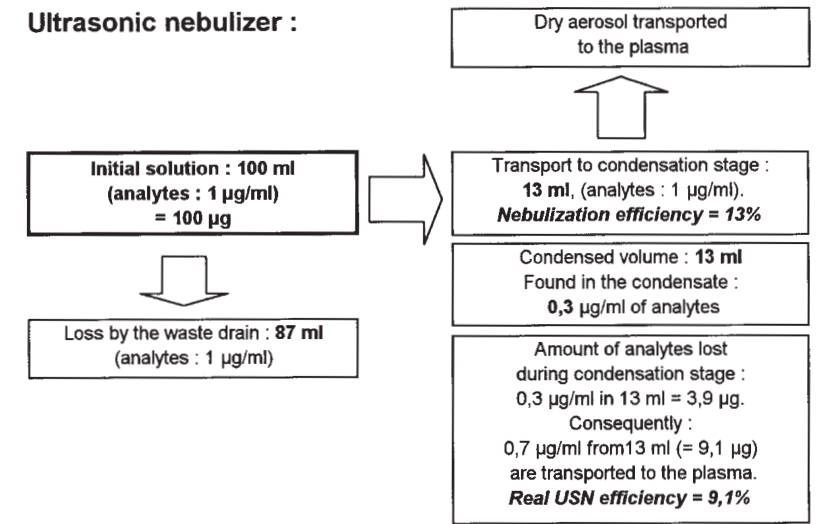

Figure 1. Evaluation of USN and PN efficiencies: scheme of processes that take place during the formation and transport of the aerosol. Multielement solution tested: As, Be, Cd, Co, Cr, Mo, Ni, $\mathrm{Pb}, \mathrm{Sb}, \mathrm{V}$ at $1 \mu \mathrm{g} / \mathrm{ml}^{-1}$ in $2 \%$ nitric acid. apparently only 3 times better than for PN. Because detection limits obtained in practice with an USN are at least 10 times lower than with a PN, it may be postulated that the wet aerosol generated by a PN is not quantitatively transported or less efficiently dissociated in the plasma, indicating then an actual efficiency probably inferior to a percent for this introduction device.

\section{Matrix effects}

\section{Responsibility of the USN principle, of the plasma loading or of both?}

Compared to pneumatic nebulizers that apparently exhibit a very good behaviour concerning matrix effects, these are much more pronounced in the analysis with an USN. To decide upon the behaviour of the analyte signal in the presence of heavy matrices, several cases may be postulated: i) differences in the aerosol formation due to changes in the viscosity or in the salt content (USN: transducer), ii) changes in the aerosol transport (USN: principally condensation stage), iii) changes in analyte dissociation and/or excitation (plasma loading). All these phenomena result in a similar observation: a progressive suppression of the analyte emission signal with increasing matrix. In principle, a classical internal standard correction should be able to compensate for all above mentioned phenomena. From previous paragraph it must be remembered that nebulization efficiency of the USN is about 8-10 times higher than in the case of the PN. This means that not only 8-10 times more analyte is transported to the plasma but that this is also true for the matrix.

We have evaluated real matrix effects exhibited by using a PN and an USN by measuring eight analytes (multielement synthetic solutions) in the presence of increasing $\mathrm{Ca}$ as interferent. For USN, the $\mathrm{Ca}$ concentration ranged from 0 to $1000 \mu \mathrm{g} \mathrm{ml}^{-1}$, for PN from 0 to $8000 \mu \mathrm{g} \mathrm{m}^{-1}$. During preliminary tests we have seen that the magnitude of the $\mathrm{Ca}$ interference is not dependent on analyte concentrations, at least for elements studied in this part of work: it was then chosen the same for both nebulization devices tested. Figure 2 shows responses of the measurement system, given in form of recoveries. At first sight it is evident that the main responsible factor for the observed interference is too high plasma loading, not the introduction system: the evolution of signal suppression is clearly dependent of the $\mathrm{Ca}$ amount attaining the plasma, indifferently of the mean of its introduction. This is rather a good image for the principle of ultrasonic nebulization, very often described as the main accountable part of the system concerning undesirable matrix effects: signal suppressions observed here are in both cases due to excessive plasma loading by calcium, resulting in an incomplete dissociation and/or excitation of analyte elements.

\section{Contribution of different main matrix elements}

As already specified in a previous work [1], the matrix of plant and animal samples may be highly variable. The main matrix elements are $\mathrm{Ca}, \mathrm{K}, \mathrm{Na}, \mathrm{Mg}$ and $\mathrm{P} ; \mathrm{K}$ and $\mathrm{Ca}$ exhibit 


\section{Original articles}

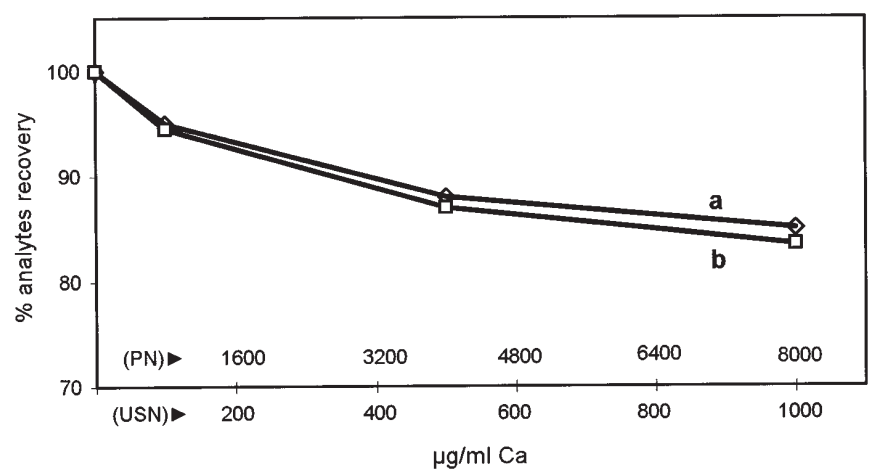

Figure 2. Average analyte signal suppression observed for pneumatic and ultrasonic nebulizers with increasing $\mathrm{Ca}$ concentrations. Taking into account considerations concerning the sample part really reaching the plasma, the $\mathrm{Ca}$ concentrations introduced were chosen 8 times higher for PN than for USN. Analytes: $0.1 \mu \mathrm{g} / \mathrm{ml}^{-1}$ (Be, Cd); $0.5 \mu \mathrm{g} / \mathrm{ml}^{-1}$ (Co, Cr, Mo, Ni, Pb, V).

the highest concentrations (up to $5 \%$ expressed in dry matter but they may be still significantly higher in some rare cases). $\mathrm{Mg}, \mathrm{P}$ and $\mathrm{Na}$ contents are generally lower in these media, up to $0.5 \%$. Mineralization procedures are usually applied to a $1 \mathrm{~g}$ sample completed to $100 \mathrm{ml}$. By this way, the matrix elements initial content is lowered by a factor of 100 in sample solutions analysed. We have often observed that with using USN and the original torch supplied by the ICP manufacturer, the application of higher weight/volume ratio is not reasonable because of possible clogging of the injector capillary by salts with possible subsequent damages on the USN transducer due to the elevation of the pressure inside the system. However, with the gas-gained torch injector utilised in this work, the limit of $1 \mathrm{~g}$ sample in $100 \mathrm{ml}$ may be significantly passed beyond without any problems due to obstruction of the torch capillary.

Because of their highest content in samples considered in this work, the most potential interferents are calcium and potassium. In a research paper concerning interference effects with using ICP-AES-USN, Budic [20] has shown changes in the analyte emission intensities in the presence of environmental matrices and has observed that matrix effects are more severe for pure calcium matrices than for potassium or complex matrices containing $\mathrm{K}, \mathrm{Na}, \mathrm{P}$ and $\mathrm{Ca}$ together. The whole problem seems to be very complex: matrix effects on analyte intensities are different for each main matrix element and depend on several factors as excitation energies, electron number density, excitation temperature, etc. For these reasons, Budic concluded that internal standardisation is inadequate for practical analysis when dealing with samples of varying matrix composition and proposed a careful matrix matching of standard solutions. In our opinion, this is not an advice that might be really applicable in a routine analysis. For this reason we have first decided to better define the actual influence of main matrix elements on emission intensities of selected analytes.
Figure 3 a suggests that calcium is responsible for main interference problems, followed by magnesium (Fig. 4a); however, in matrices studied, magnesium is present at lower concentrations and its influence is consequently almost negligible. A similar conclusion may be postulated for potassium that may be present at relatively high concentrations but without significant influence on analytes emission (Fig. 4b).

\section{Possible corrections}

In previous paragraph we have shown that calcium is the most potential interferent in trace element analysis of environmental samples. Figure $3 \mathrm{a}$ indicates the average analyte signal suppression with increasing $\mathrm{Ca}$ concentrations and the observed emission signal suppression for two types of internal standards (argon emission line and scandium in solution), measured under the same conditions (Fig. 3b). By comparison of shapes of these curves it appears that the accuracy of Sc correction has to be better, but also that in both cases a complete correction cannot be attained for the highest calcium concentrations. Nevertheless, this example does not take into account the possible synergic influence of other matrix elements and any general conclusion cannot be then emitted in this case.

To better illustrate this problematic, we have done a representative selection of plant and marine organisms usually
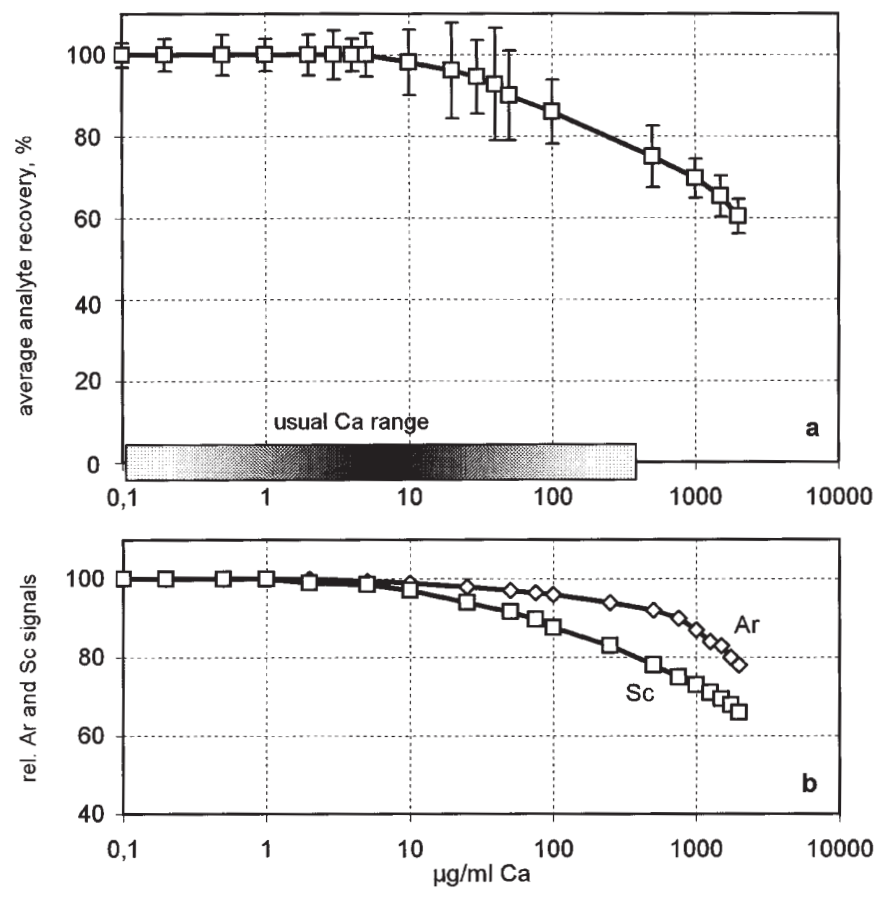

Figure 3. Effect of Ca: average suppression of emission intensities for analytes (a) and two (Ar, Sc) internal standards (b) with increasing concentrations of Ca. Analytes: $0.1 \mu \mathrm{g} / \mathrm{ml}^{-1}$ (Be, Cd); $0.5 \mu \mathrm{g} / \mathrm{ml}^{-1}$ (Co, Cr, Mo, Ni, Pb, V). 

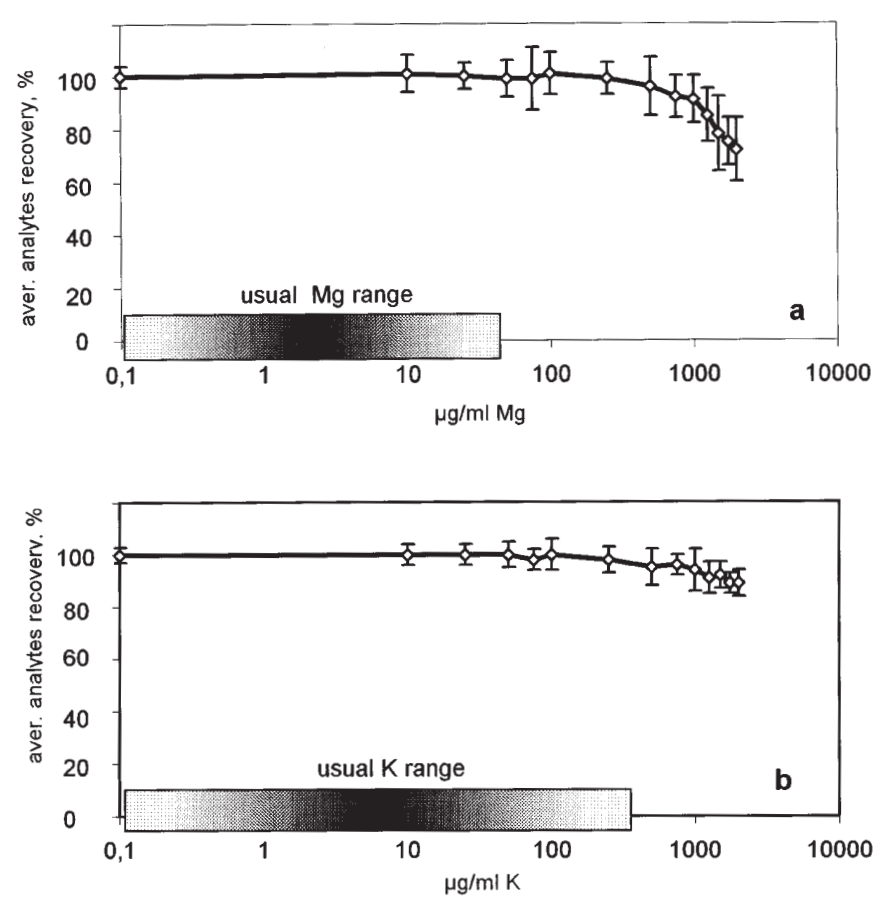

Figure 4. Effect of main matrix elements on analyte recoveries: $\mathrm{Mg}$ (a); K (b). Analytes: $0.1 \mu \mathrm{g} / \mathrm{ml}^{-1}$ (Be, Cd); $0.5 \mu \mathrm{g} / \mathrm{ml}^{-1}$ (Co, $\mathrm{Cr}, \mathrm{Mo}, \mathrm{Ni}, \mathrm{Pb}, \mathrm{V})$.

analysed in our monitoring programs and classified them with increasing Ca content (Fig. 5). This represents 28 very different matrices in which calcium expressed in dry matter ranges between 0 and $20 \%$ ( $=$ up to $2000 \mu \mathrm{g} / \mathrm{ml}^{-1}$ in solution for a mineralization of $1 \mathrm{~g}$ sample in $100 \mathrm{ml}$ ). However, the four samples with the most elevated $\mathrm{Ca}$ concentrations must be considered as rarely encountered extremes because a calcareous carapace composes them. In this figure we are also indicated total inorganic matrix composition of selected samples $(\mathrm{Ca}+\mathrm{K}+\mathrm{P}+\mathrm{Mg}+\mathrm{Na}$, dotted area) and for each sample studied the emission signal evolution for the two types of IS tested. From aspects of these curves it seems that an IS correction by Ar and especially by Sc might be successful, but only for Ca content up to about $50 \mathrm{~g} / \mathrm{kg}^{-1}$ dry matter $\left(=500 \mu \mathrm{g} / \mathrm{ml}^{-1}\right.$ in solution), performance generally sufficient for usual environmental monitoring cases. Of course, the internal standard correction by Sc may be considered as more secure because it takes into account not only phenomena occurring in the plasma but also those which can possibly take place in the introduction system. This is expressed in figure 6 which compares efficiencies of both IS correction modes, showing clearly the better corrective power of Sc.

The validation of the whole plant analysis including the ICP-AES-USN method with internal standardisation has been already presented for several plant reference materials in previous papers $[1,6,21]$. Concerning this point it must be specified that residual errors observed after IS correction are generally included in the uncertainty range of recommended values given for trace elements considered. It is consequently difficult to give here more detailed conclusions concerning an possible improvement of accuracies in such validations.

Finally, also a correction using a calculation based on the calcium content in the sample has been envisaged. In this case, $\mathrm{Ca}$ was measured together with other analytes. A correction of analyte responses was then applied using a common factor based on previously measured and defined changes in analyte calibration curve slopes with varying $\mathrm{Ca}$ content. Such a correction leads to significant improvement of results (Fig. 7), but day-to-day changing plasma or/and nebulization conditions should imply a frequent checking for

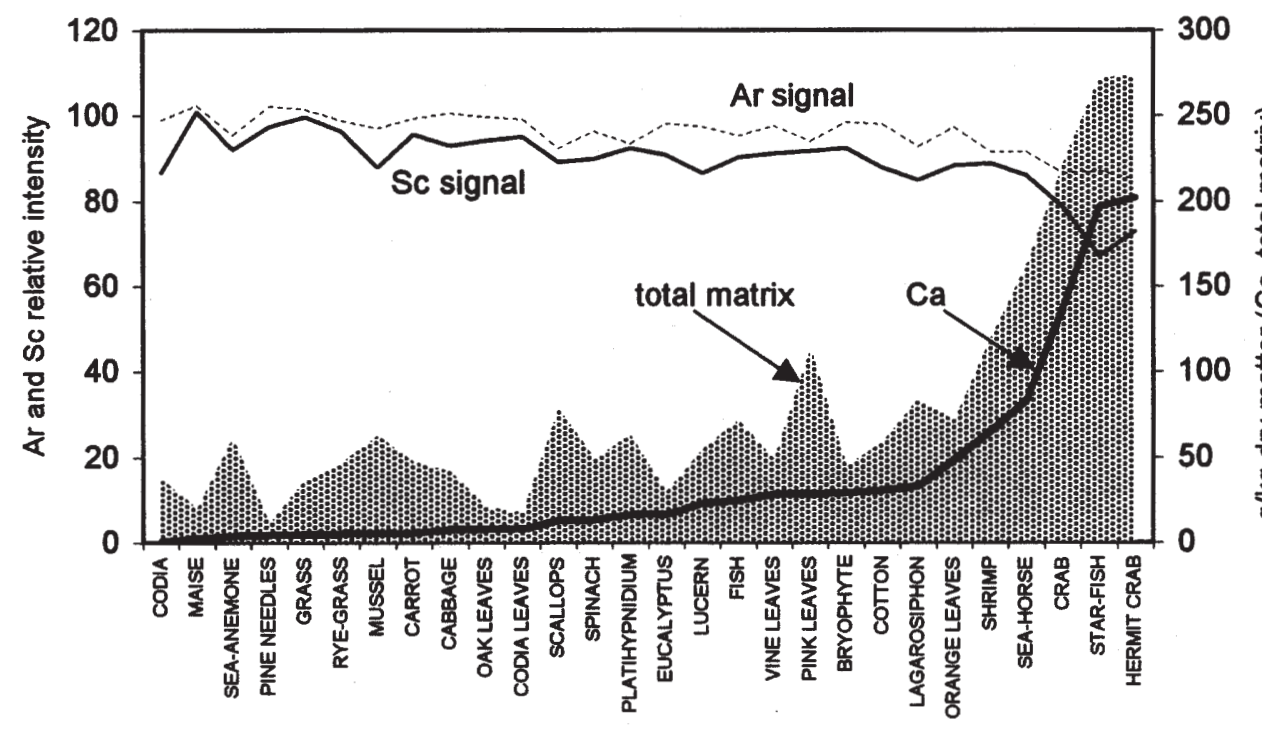

Figure 5. Calcium (heavy line) and total matrix (dotted area) contents in real samples and evolution of internalstandard emission intensities. 


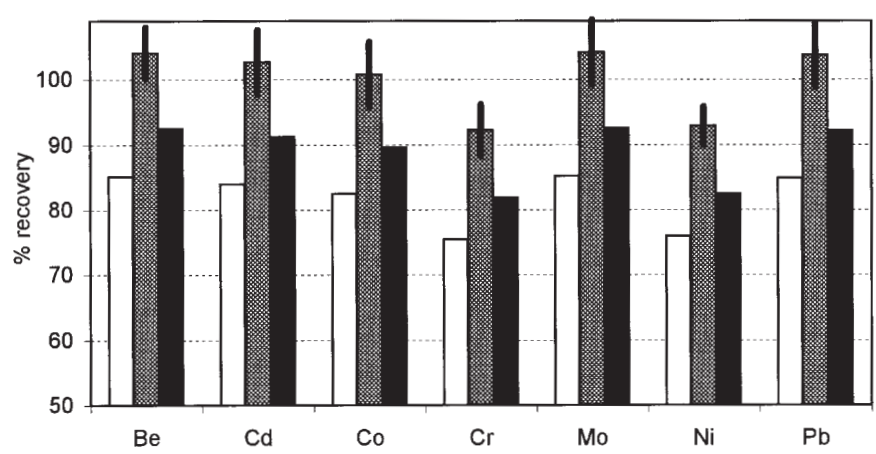

Figure 6. Internal standard correction for real environmental samples (4 plants, Ca-content in solution between 50 and $1000 \mu \mathrm{g} / \mathrm{ml}^{-1}$ ). Without correction (empty columns), Ar correction (black columns) and Sc correction (dotted columns: average recoveries and standard deviation).

validity of the initially defined correction factor. Moreover, such unavoidable time-consuming procedure is also in contradiction with practical needs of a routine analysis.

\section{Particular cases of copper and boron}

During present work we have observed that behaviour of all trace elements is similar concerning the magnitude of interference effects provoked by environmental matrices studied. One remarkable exception was nevertheless noticed for copper. Using ultrasonic nebulization, the behaviour of $\mathrm{Cu}$ in the presence of $\mathrm{Ca}$ differs significantly from those of other analytes (Fig. 8). For a Cu concentration of $0.5 \mu \mathrm{g} / \mathrm{ml}^{-1}$, its signal suppression starts earlier, with fractions of $\mu \mathrm{g} \mathrm{Ca} / \mathrm{ml}^{-1}$ only. With increasing $\mathrm{Ca}$ concentration, the $\mathrm{Cu}$ emission signal drastically decreases and attains a plateau at $2 / 5$ of its initial value already in the presence of $5 \mu \mathrm{g} \mathrm{Ca} / \mathrm{ml}^{-1}$. After this point no supplementary suppression occurs (Fig. 8a). A similar situation was observed with ten-fold higher concentration of $\mathrm{Cu}$ but the beginning of the plateau is shifted to $50 \mu \mathrm{g} \mathrm{Ca} / \mathrm{ml}^{-1}$ (Fig. 8b). This means that extent of this interference depends on actual concentrations of both $\mathrm{Ca}$ and $\mathrm{Cu}$, indicating then a chemical process which take place between these elements during the USN condensation stage. An IS correction is inadequate in this case because the IS and the analyte elements exhibit a completely different behaviour. In practice, such a case is very difficult to manage and it may lead to completely erroneous results. For this reason, we recommend avoiding the USN for copper determinations in matrices with $\mathrm{Ca}$ and suggest to use less sensitive but more secure pneumatic devices in which the described interference does not appear and the behaviour of copper is similar as for other analytes studied (Fig. 8c).

Such a case is not unique in the ICP-AES-USN analysis: the behaviour of boron, even without interferent, is still more serious: its emission intensity is about ten times lower using USN than with PN. Considering above mentioned efficiencies for these two nebulization devices, the actual

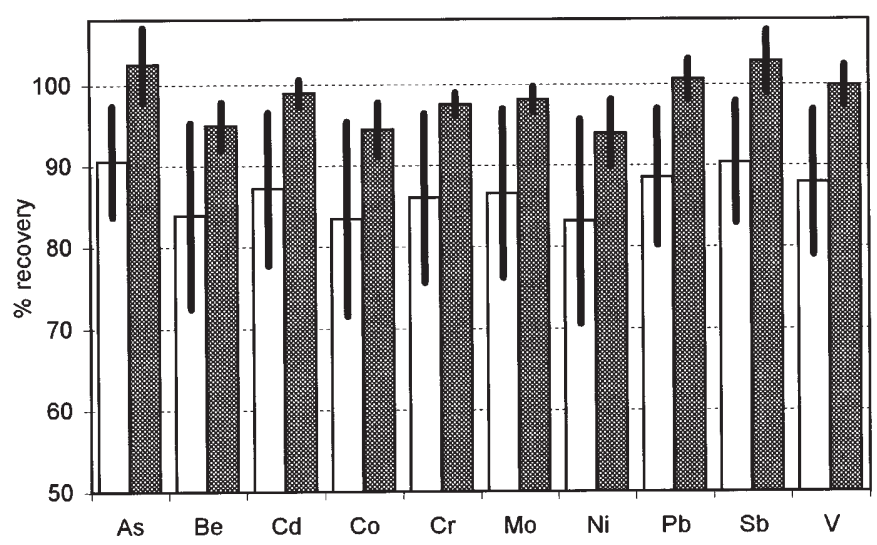

Figure 7. Correction using calcium content in the sample as IS. Synthetic samples, Ca content between 100 and $2000 \mu \mathrm{g} / \mathrm{ml}^{-1}$, analytes: $0.1 \mu \mathrm{g} / \mathrm{ml}^{-1}$ (Be, Cd); $0.5 \mu \mathrm{g} / \mathrm{ml}^{-1}$ (As, Co, Cr, Mo, Ni, Pb, $\mathrm{Sb}, \mathrm{V}$ ). Without correction (empty columns: average recoveries and standard deviation), Ca correction (dotted columns: average recoveries and standard deviation).
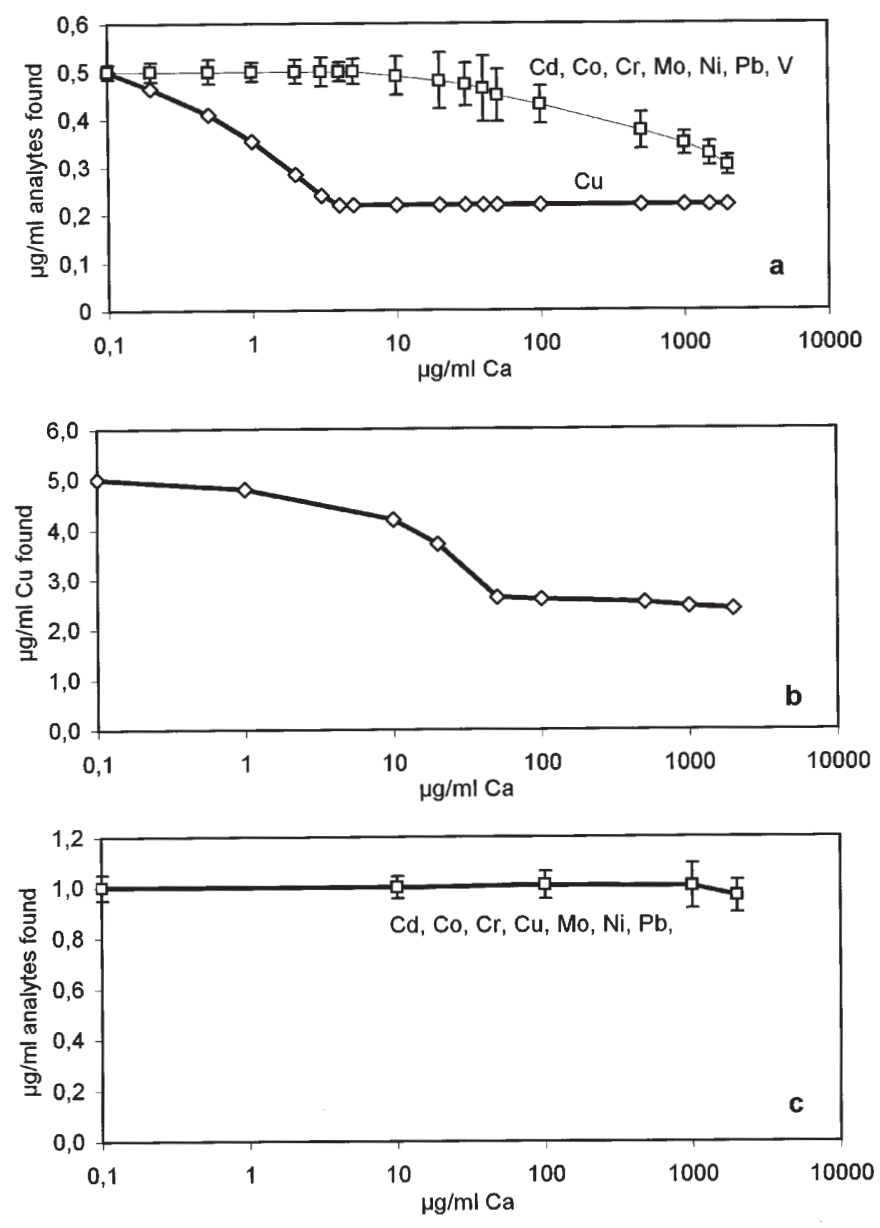

Figure 8. Particular behaviour of copper with increasing Ca concentrations. a: USN, $\mathrm{Cu} 0.5 \mu \mathrm{g} / \mathrm{ml}^{-1}$ (broken line = other analytes); b: USN, Cu $5.0 \mu \mathrm{g} / \mathrm{ml}^{-1}$, c: PN, Cu $1.0 \mu \mathrm{g} / \mathrm{ml}^{-1}$. 
emission intensity loss for boron is then of two orders of magnitude using USN. For this particular case of boron an explanation exists [22,23]: in the presence of nitric acid always added to standards and samples (stabilisation, mineralisation), there is formation of boric acid which condenses in a large part during the cooling stage of the USN prior to its evacuation under this chemical form to the waste. This was confirmed by analysing of the waste from the USN condensation stage in which more than $85 \%$ of boron was recovered.

\section{Conclusions}

Considerations emitted here lead to following conclusions: trace element ICP-AES-USN analyses of environmental matrices are disturbed principally by high and variable calcium contents in samples. These effects are essentially due to excessive plasma loading ensured by the high USN efficiency. Other main matrix elements play a less important role when they are considered individually. Of course, in a real analysis their possible synergic effects with $\mathrm{Ca}$ remain probable. For a significant improvement of the accuracy in routine trace element analyses, a classical internal standardisation may be very useful but some precautions must be taken especially for samples with very elevated calcium concentrations presented e.g. in crustaceans. Determinations of copper and boron have to be performed exclusively by using pneumatic nebulization devices because chemical reactions occurring in the USN condensation stage lead to significant losses of these analytes.

\section{References}

1. Hoenig, M.H.; Docekalová, H.; Baeten, H. J. Anal. At. Spectrom. 1998, 13, 195-199.

2. Goulden, P.D.; Anthony, D.H.J. Anal. Chem. 1984, 56, 23272329.
3. Fassel, V.A.; Bear, B.R. Spectrochim. Acta, Part B 1986, 41, 1089-1113.

4. Olson, K.W.; Haas, W.J.; Fassel, V.A. Anal. Chem. 1977, 49, 632-637.

5. Carré, M.; Lebas, K.; Marichy, M.; Mermet, M.; Poussel, E.; Mermet, J.-M. Spectrochim. Acta, Part B 1995, 50, 271-283.

6. Hoenig, M.; Baeten, H.; Vanhentenrijk, S.; Ploegaerts, G.; Bertholet, T. Analusis 1997, 25, 13-19.

7. Clément, A.; Bréchet, C.; Geoffroi, M. Analusis, 1994, 22, 311-325.

8. Barnett, W.B.; Fassel, V.A.; Kniseley, R.N. Spectrochim. Acta, Part B 1968, 23, 643-664.

9. Barnett, W.B.; Fassel, V.A.; Kniseley, R.N. Spectrochim. Acta, Part B 1970, 25, 139-161.

10. Watters, R.L.Jr.; Norris, J.A. In Application of ICP to Emission Spectroscopy; Barnes, R., Ed., Philadelphia: Franklin Inst., 1979, pp 65-81.

11. Li, J. J. Anal. At. Spectrom. 1996, 11, 683-687.

12. Wallace, G.F. Atom. Spectrosc. 1984, 5, 5-9.

13. Uchida, H.; Nojiri, Y.; Haragushi, H.; Fuwa, K. Anal. Chim. Acta 1981, 123, 57-63.

14. Skogerboe, R.K.; Coleman, G.N. Appl. Spectrosc. 1976, 30, 504-507.

15. Schmidt, G.J.; Slavin, W. Anal. Chem. 1982, 54, 2491-2495.

16. Garden, L.M.; Marshall, J.; Littlejohn, D. J. Anal. At. Spectrom. 1991, 6, 159-163.

17. Mermet, J.-M.; Ivaldi J.C. J. Anal. At. Spectrom. 1993, 8, 795801.

18. Lorber, A.; Goldbart, Z.; Harel, A.; Sharvit, E.; Eldan, M. Spectrochim. Acta, Part B 1986, 41, 105-113.

19. CII, presented in Fresenius' J. Anal. Chem. 1993, 345, 230233.

20. Budic, B. J. Anal. At. Spectrom. 1998, 13, 869-874.

21. Hoenig, M.; Baeten, H.; Vanhentenrijk, S.; Vassileva, E.; Quevauviller, Ph. Anal. Chim. Acta 1998, 358, 85-94.

22. Feldman, C. Anal. Chem. 1961, 33, 1916-1920.

23. Vláxil, F.; Drbal, K. Chem. Listy 1968, 62, 1371-1403. 